\section{Contemporaneidade, escalas e lugares - panoramas dos estudos de população e ambiente na atualidade}

\section{Thais Tartalha do Nascimento Lombardi ${ }^{*}$}

\author{
D'ANTONA, Álvaro de Oliveira; \\ CARMO, Roberto Luiz (Orgs.). \\ Dinâmicas demográficas e am- \\ biente. Campinas: Nepo/Unicamp, \\ 2010.
}

Oferecer um panorama dos estudos e pesquisas realizados pela linha de População e Ambiente, do Núcleo de Estudos de População (Nepo) da Unicamp, esta é a proposta dessa coletânea organizada por D'Antona e Carmo. Porém, desde logo na introdução, percebe-se que a proposta é não só expor trabalhos, mas também mostrar a necessidade de um cuidado teórico e metodológico ao se trabalharem as ideias e os problemas. Com isso, o livro já contribui por ser uma compilação de temáticas tratadas no âmbito do Nepo e também daquelas que são caras à área de População e Ambiente em geral, demonstrando como componentes da dinâmica demográfica podem ser trabalhados para se apreender a relação entre a população e o ambiente.

Ao longo dos artigos percebe-se que o diálogo é uma constante tanto nas pesquisas das várias linhas dentro do Nepo como em outras fora dele, mostrando a atenção voltada aos trabalhos desenvolvidos no Brasil e fora dele. Resultado desse diálogo é a força argumentativa que ganham os textos ao sustentar suas problemáticas a partir não apenas de recortes interessantes, mas também da consistência teórica e temáticas atuais. Isso fica explícito na organização dos capítulos do livro a partir de componentes demográficos e temáticas interdisciplinares. Preocupados em entender e discutir a dinâmica populacional, a mobilidade, a distribuição espacial e o crescimento da população vis-à-vis processos de urbanização, mudanças climáticas, risco e vulnerabilidade, entre outros, os trabalhos são capazes de perpassar diversas regiões e biomas do Brasil, oferecendo, assim, discussões sobre temas caros a toda a Demografia e para além dela.

Dessa forma, o livro é aberto com uma introdução dos organizadores, na qual discutem a transição demográfica e a questão ambiental, mostrando como os debates e problemas da Demografia podem ser pensados à luz da relação população e ambiente no que tange à localização, distribuição no espaço e uso dos recursos pela população. Já nessa introdução, D’Antona e Carmo chamam a atenção para a forma pela qual os artigos se preocupam com processos que implicam mudanças no espaço e na dinâmica da população. Com isso, os organizadores conseguem dizer que há um paradigma do campo que permeia também a Demografia como um todo, que é a necessidade de incluir escalas, temporalidades e lugares para se pensar a dinâmica da população. Isto pois, se há múltiplas dinâmicas, particulares a cada população, entender como estas se desdobram ao longo do tempo e no espaço é fundamental para que seja possível reconstruir processos, entender a realidade que se observa, ou saber quais dados ou metodologias podem fornecer melhores ferramentas de análise.

Assim, o primeiro bloco de artigos está reunido sob o título "Urbanização e dinâmica demográfica". O trabalho de Alex Manetta versa sobre como a mobilidade populacional e os impactos ambientais intraurbanos se dão na região fronteiriça de Corumbá, enquanto o estudo de Henrique Frey aborda a forma como a urbanização em Sorocaba

\footnotetext{
* Doutoranda em Demografia do Programa de Pós-Graduação em Demografia do IFCH-Unicamp, mestre em Antropologia Social e editora da Ruris - Revista do Centro de Estudos Rurais (Ceres-Unicamp).
} 
alterou e foi alterada pela dinâmica demográfica que lá se instaurou.

No segundo bloco de artigos, agrupados sob o título "Distribuição populacional e ambiente na Amazônia", o texto de Julia Côrtes procura pensar como alterações na mobilidade e na distribuição da população ajudam a reconfigurar o meio rural no Pará, incorporando análises longitudinais que ajudam a reconstruir o espaço onde a dinâmica populacional se realiza. Já o estudo de Maria do Carmo Bueno e Ricardo Dagnino constata problemas em se caracterizar populações em unidades de conservação, e busca abordar métodos para obter melhores dados para aferição de características destas populações a partir da contagem de 2007, considerando a importância ambiental e social dessas áreas e a necessidade de ter ferramentais de qualidade para melhor elaboração de políticas públicas nessas localidades. Por fim, o trabalho de Vinícius Côrrea e Roberto do Carmo se propõe a pensar as relações entre o setor de mineração, no Pará, e a dinâmica da população, procurando caracterizar tais relações. A importância dessa reflexão reside no fato de que as características do setor de mineração e seus impactos na população e no ambiente estão longe de serem exaustivamente trabalhados.

O terceiro bloco, denominado "Risco, vulnerabilidade e lugar", é aberto com o artigo de Diomário Cerqueira, que procura pensar em como os estudos de riscos e vulnerabilidades prescindem também de elementos de uma microescala. Esta é parte de um conjunto de elementos para se entender a dimensão demográfica e ambiental desses fenômenos e suas relações desde a escala local, passando pela regional até a global. Dando sequência a esse artigo, está o trabalho de Luiz Tiago de Paula e Eduardo Marandola Jr., que, também discutindo a temática da vulnerabilidade, vão tratá-la através da chave da memória e da experiência. Apreendendo a vulnerabilidade como multidimensional, os autores pretendem enfocar o fato de que outros elementos, como a memória e a experiência, são tão necessários ao entendimento da relação entre população e ambiente quanto o macro agregado de dados. Fechando esse bloco, está o texto de Fernanda de Paula, que recorta nos bairros a discussão sobre riscos e perigos. Ela faz o bairro ter a possibilidade de ser uma unidade espacial de generalização dos dados, além de ser um lugar entorno do qual as pessoas realizam suas experiências cotidianas e urbanas. Com isso, a autora demonstra como as duas dimensões - a da experiência e do macro agregado de dados - são importantes para a análise de riscos, perigos e vulnerabilidade.

Encerrando o livro, o bloco denominado "População e mudanças climáticas" traz três textos. O primeiro, de Francine Modesto, retoma, à luz das discussões sobre as mudanças climáticas, a crítica a equações simplistas que tomam o volume populacional versus o ambiente como problema, mascarando outros elementos, como mudanças no padrão de produção e consumo ou as alterações na dinâmica demográfica local, regional e mundial em relação às mudanças ambientais globais. Essa reflexão, que chama a atenção para uma discussão que se imaginava superada e em que a análise demográfica acurada tem importância na sua desmistificação, abre o bloco para os dois artigos seguintes. $O$ estudo de Robson Bonifácio da Silva e Ricardo Ojima preocupa-se em discutir população e ambiente à luz de dois processos importantes do mundo contemporâneo: a urbanização e as mudanças climáticas. Ambos processos foram acompanhados por mudanças na dinâmica demográfica e no ambiente e se constituíram em movimentos simbióticos, ao impactarem e serem impactados uns pelos outros. Para fechar o conjunto de artigos, está o texto de Cesar Marques que, apesar de trabalhar a temática das mudanças climáticas, o faz em diálogo com a questão dos riscos, a partir da elaboração de gradações entre áreas mais ou menos expostas aos - ou em situação de - riscos, relacionando característica do ambiente com aspectos sociodemográficos. Com isso, o autor demonstra a importância de serem pensados os vários fatores que são necessários para as análises dos riscos aos quais populações em áreas costeiras estão sujeitas devido às próprias caracte- 
rísticas físicas do ambiente e estas em face das mudanças climáticas.

Todos os artigos têm uma qualidade importante, que é sua capacidade de apontar caminhos a serem trilhados pelas temáticas às quais se dedicaram. Interessante perceber que, em vários textos, a emergência de elaboração de novas metodologias de apreensão de dados - pela necessidade ou importância dos dados qualitativos ou em microescala - ou a incorporação de outros elementos da dinâmica demográfica, como a fecundidade, mortalidade, ou arranjos familiares, estão apontadas e se mostram como questões para as novas pesquisas. Isso ajuda a indicar um caminho ainda a ser percorrido no entendimento da relação entre a população e o ambiente, sem deixar de pensar nas relações entre os componentes da dinâmica demográfica e os elementos ambientais (entendidos como abrangendo tanto o ambiente natural como o construído e os elementos climáticos e físicos que os compõem).

Assim, ao fim da leitura dessa compilação de artigos, percebe-se como a linha de pesquisa de População e Ambiente do Nepo está focada em elaborar pesquisas e estudos em sintonia com questões contemporâneas de grande importância. É notável também como são tratadas tais questões com cuidado analítico, teórico e metodológico, apontando inclusive caminhos a serem trabalhados a partir das falhas encontradas nas discussões com os dados, debates e metodologias disponíveis. Grande parte dessa capacidade de sintonia com discussões contemporâneas e o cuidado analítico devem-se ao fundador dessa linha de pesquisa, o prof. Daniel J. Hogan, que de 1983 até 2010 - ano em que faleceu - motivou e instruiu os alunos e pesquisadores do Nepo.

Por meio de sua capacidade de fomentar o trabalho em equipe e imprimir as características que se destacam em todos os trabalhos dessa coletânea, Hogan incutiu na linha de pesquisa qualidades que são sua herança e melhores aspectos cultivados pelos que são ou foram da linha de pesquisa. Com certeza, este é um livro-exemplo de um bom trabalho em equipe.

Recebido para publicação em 30/06/2011 Aceito para publicação em 01/08/2011 